\title{
Melatonin Attenuates Oxidative Damage Induced by Acrylamide In Vitro and In Vivo
}

\author{
Xiaoqi Pan, ${ }^{1,2}$ Lanlan Zhu, ${ }^{3}$ Huiping Lu, ${ }^{4}$ Dun Wang, ${ }^{1}$ Qing Lu, ${ }^{2}$ and Hong Yan ${ }^{1}$ \\ ${ }^{1}$ Department of Health Toxicology, MOE Key Lab of Environment and Health, School of Public Health, Tongji Medical College, \\ Huazhong University of Science and Technology, Wuhan 430030, China \\ ${ }^{2}$ Institute for Environmental Medicine, MOE Key Lab of Environment and Health, School of Public Health, Tongji Medical College, \\ Huazhong University of Science and Technology, Wuhan 430030, China \\ ${ }^{3}$ Sanya Center for Disease Control and Prevention, Hainan 572000, China \\ ${ }^{4}$ Shanghai Songjiang District Center for Disease Control and Prevention, Shanghai 200000, China \\ Correspondence should be addressed to Hong Yan; yanhong@mails.tjmu.edu.cn
}

Received 17 April 2015; Revised 30 May 2015; Accepted 4 June 2015

Academic Editor: José L. Quiles

Copyright @ 2015 Xiaoqi Pan et al. This is an open access article distributed under the Creative Commons Attribution License, which permits unrestricted use, distribution, and reproduction in any medium, provided the original work is properly cited.

\begin{abstract}
Acrylamide (ACR) has been classified as a neurotoxic agent in animals and humans. Melatonin (MT) has been shown to be potentially effective in preventing oxidative stress related neurodegenerative disorders. In this study, whether MT exerted a protective effect against ACR-induced oxidative damage was investigated. Results in cells showed that reactive oxygen species (ROS) and malondialdehyde (MDA) significantly increased after ACR treatment for $24 \mathrm{~h}$. MT preconditioning or cotreatment with ACR reduced ROS and MDA products, whereas the inhibitory effect of MT on oxidant generation was attenuated by blocking the MT receptor. Increased DNA fragmentation caused by ACR was significantly decreased by MT coadministration. In vivo, rats at $40 \mathrm{mg} / \mathrm{kg} /$ day ACR by gavage for 12 days showed weight loss and gait abnormality, Purkinje cell nuclear condensation, and DNA damage in rat cerebellum. MT (i.p) cotreatment with ACR not only recovered weight and gait of rats, but also decreased nuclear condensation and DNA damage in rat cerebellum. Using MDA generation, glutathione (GSH) level, superoxide dismutase (SOD), and glutathione peroxidase (GSH-Px) activities in rat cerebellum as indicators, MT alleviated ACR-induced lipid peroxidation and depressed antioxidant capacity. Our results suggest that MT effectively prevents oxidative damage induced by ACR.
\end{abstract}

\section{Introduction}

Acrylamide (ACR) has been widely used in various industrial settings, such as wastewater management, cosmetic manufacturing, dye synthesis, and scientific laboratories for the electrophoretic separation of macromolecules. ACR is found to be present in starchy food under high temperature $[1,2]$. As a well-documented neurotoxic agent in both humans and laboratory animals, its existence is a worldwide concern [3]. Subchronic, low-level occupational human exposure to ACR can lead to neurotoxicity characterized by ataxia, skeletal muscle weakness, and numbness of the hands and feet. Many studies have indicated that rats treated orally with ACR at $20 \sim 50 \mathrm{mg} / \mathrm{kg} /$ day can produce cumulative neurotoxicity, primarily exhibiting gait abnormality [4-6]. As is well known, the cerebral cortex is one of the advanced areas in the nervous system, and it controls sensory and movement in humans and animals, whereas the cerebellum maintains the balance and coordination of the body. However, the exact mechanism underlying ACR neurotoxicity remains unclear.

Oxidative damage has been suggested to be one of the mechanisms of neurotoxicity induced by ACR [7]. An imbalance between the overproduction of reactive oxygen species (ROS) and elimination of free radicals induces oxidative damage. Excesses in free radical generation induced by oxidative metabolism imbalance result in a series of changes, including protein and DNA injury, energy deficiency, inflammation, and mitochondrial dysfunction. Some studies have suggested that ACR can lead to an imbalance in nervous tissue and the sciatic nerve by enhancing lipid peroxidation and reducing antioxidant capacity, as evidenced by enhanced levels of ROS and MDA, accompanied with a decrease in the 
levels of superoxide scavenging enzymes SOD, catalase, and glutathione peroxidase (GSH-Px) [8-10].

Melatonin (MT), an efficient free radical scavenger, is the main hormone secreted by the pineal gland. It has been found to exert protective effects on a number of pathological damages including shock, ischemia reperfusion, and inflammation [11, 12]. In addition, MT is a potent free radical scavenger with a broad spectrum of antioxidant capacity [13-16]. It readily crosses various physiological barriers because of its high lipophilicity and hydrophilicity, such as the blood-brain barrier. Thus, its pharmacological use may potentially protect against oxidative damage existing anywhere in the organism. MT plays a crucial role in preventing oxidative damage of biological macromolecules caused by oxidative substance and protecting the vitality of antioxidant enzymes in the body [14]. Considering the proposed dosage of MT (1 3 mg) in prevention and based on previous studies, MT at doses of 5$10 \mathrm{mg} / \mathrm{kg}$ exhibited an effective cellular antioxidation capacity $[17,18]$. The absolute bioavailability of MT ranges from $1 \%$ to $37 \%$ (mean $=8.6 \% \sim 3.9 \%$ and $16.8 \% \sim 12.7 \%$ for male and female subjects, resp.) [19].

In this study, ACR-poisoning models were established both in vitro and in vivo. To explore whether MT intervention can alleviate oxidative damage induced by ACR, oxidative and antioxidative parameters including ROS production, glutathione (GSH) consumption, and SOD and GSH-Px activities, as well as neurological impairment, morphological alteration, and DNA damage, were assayed. Moreover, luzindole (a novel MT receptor antagonist) was added to further study the possible mechanism of MT intervention in vitro. Luzindole acts as a selective MT receptor antagonist, with approximately 11 25-fold greater affinity for the MT receptors [20]. Conclusions of the paper will provide evidence for the chemoprevention of ACR toxicity.

\section{Materials and Methods}

2.1. Chemicals and Materials. Acrylamide (ACR), melatonin (MT), and other chemicals (all 99.9\% purity) were obtained from Sigma Chemical Co. All solvents were of analytical grade and Milli-Q water was used throughout the analyses. Malonaldehyde (MDA), superoxide dismutase (SOD), glutathione $(\mathrm{GSH})$, and glutathione peroxidase (GSH$\mathrm{Px}$ ) detection kits were provided by the Nanjing Jiancheng Bioengineering Institute (Nanjing, China). Fluorescent probe 2,7-dichlorofluorescein diacetate (DCFH-DA), Hoechst 33258 dye, normal-melting-point agarose (NMPA) gel, lowmelting-point agarose (LMPA) gel, and ethidium bromide (EB) were from Sigma Co. RPMI-1640 culture medium and fetal bovine serum were purchased from GIBCO. 3-(4,5Dimethylthiazol-2-yl)-2,5-diphenyltetrazolium (MTT) cell viability assay kit was from Promoter Biotechnology Inc. (Nanjing, China).

2.2. Cell Culture. Well-differentiated rat pheochromocytoma (PC12) cells induced by nerve growth factor were obtained from Shanghai Institutes for Biological Sciences, Chinese Academy of Cell Resource Center (Shanghai, China). Cells were maintained in RPMI-1640 with 10\% heat-inactivated fetal bovine serum (FBS) (containing $100 \mathrm{U} / \mathrm{mL}$ penicillin and $100 \mathrm{U} / \mathrm{mL}$ streptomycin) and incubated at $37^{\circ} \mathrm{C}$ with $5 \%$ $\mathrm{CO}_{2}$. Culture medium was renewed every 2 days. Cells were collected and new culture bottles were seeded every 3 days. After incubation for $24 \mathrm{~h}$, the cells were cultured with serumfree medium containing different concentrations $(1.25,2.5$, and $5 \mathrm{mmol} / \mathrm{L}$ ) of ACR dissolved in water for $1,3,6,12$, and $24 \mathrm{~h}$. MT was dissolved in absolute ethanol. The cells in the vehicle control group were incubated with culture containing a final concentration of $0.1 \%$ ethanol, as well as in the experimental groups. Intervention with MT $(50 \mu \mathrm{mol} / \mathrm{L})$ in cells was conducted at pre- $24 \mathrm{~h}$, simultaneously, and post$3 \mathrm{~h}$ with ACR $(2.5 \mathrm{mmol} / \mathrm{L})$ for the following experiments.

2.3. Cell Viability Assay. Cell viability was measured indirectly by MTT assay. PC12 cells were seeded in a 96well plate at a density of $2 \times 10^{5}$ cells/well in RPMI-1640 containing $10 \%$ FBS. The medium was replaced with the same medium containing ACR, or ACR with MT, whereas control cells were grown in RPMI-1640 containing equal water solvent. After incubation for $24 \mathrm{~h}$, cells were treated with MTT solution for $4 \mathrm{~h}$ at $37^{\circ} \mathrm{C}$. The solution was then removed, and formazan crystals were dissolved in dimethyl sulfoxide (DMSO) solutions. The absorbance at $490 \mathrm{~nm}$ was determined in a microplate reader. The results are expressed as the percentage of MTT reduction relative to the absorbance of control cells.

2.4. Animal Treatment. Healthy adult Sprague-Dawley male rats (6 7 weeks, 180 200 g) were obtained from the experimental animal center of Tongji Medical College, Huazhong University of Science and Technology in China. Individual weights were recorded, and detailed physical examinations were performed during the one-week adaptation period to ensure that animals were healthy. Each 3 rats were housed in a cage, experienced a 7-days adaptation period, and all rats were given free access to commercial laboratory feed and tap water during the nonexposure period. Rats were divided randomly into 4 groups $(n=9)$, namely, control group, ACR group, MT group, and MT + ACR cotreatment group.

ACR was dissolved in normal saline, whereas MT was dissolved in absolute ethanol and then diluted in saline to obtain a final alcohol concentration of $1 \%$ ethanol. MT $(5 \mathrm{mg} / \mathrm{kg} / \mathrm{day}$, i.p) or vehicle ( $1 \%$ alcohol in saline) was administered $5 \mathrm{~min}$ prior to ACR ( $40 \mathrm{mg} / \mathrm{kg} \mathrm{b}$. w/day) oral administration for 12 days. The body weights were determined every 3 days. After $24 \mathrm{~h}$ following the last administration, rats were sacrificed for science. All organs were separated on ice and saved at $80^{\circ} \mathrm{C}$ for the next test. The study was performed in accordance with the guidelines for the care and use of laboratory animals, prepared by the National Institute of Health, USA (Guide for the Care and Use of Laboratory Animals, 1996).

2.5. Behavioral Index (Gait Scores) Examination in Rats. Gait scores were examined according to a previously described method [33]. On days $0,3,6,9$, and 12 of ACR with or without MT and luzindole cotreatment, rats were placed in the ground and allowed freedom of movement. Each one was observed for $3 \mathrm{~min}$, and the gait score was assessed in terms 
of the following standards: 1: an unaffected or normal gait; 2: a slightly affected gait (hind limb weakness, slight ataxia, and foot splay); 3: a moderately affected gait (less active, foot splay with moderate limb spread during ambulation); and 4: a severely affected gait (foot splay, severe hind limb weakness, dragging hind limbs, and inability to rear).

2.6. Immunohistochemistry for Morphological Observation. Immunohistochemistry was used for morphological changes in rat brain tissues. The sagittal plane of rat cerebellum or cortex was fixed with $10 \%$ formaldehyde. The samples were dehydrated orderly in a series of ethanol concentrations (75\%, 85\%, 90\%, and 95\%) for $2 \mathrm{~h}$ each time and in absolute ethanol for $1.5 \mathrm{~h}$. A total of 116 samples were soaked in xylene twice for $30 \mathrm{~min}$ each time to increase the transparency of samples. Thereafter, samples were placed into melted soft wax for $15 \mathrm{~min}$. After specimens were embedded by a paraffin embedding apparatus, they were cut into slices at $37^{\circ} \mathrm{C}$ overnight. Slices were transferred into xylene for $15 \mathrm{~min}$ twice to remove paraffin. Subsequently, slices were rinsed by ethanol $(100 \%, 95 \%, 90 \%$, and $85 \%)$ in turn, stained by hematoxylin for $3 \mathrm{~min}$, differentiated by hydrochloric acidalcohol for $20 \mathrm{~s}$, and stained by eosin for $40 \mathrm{~s}$. Slices were dehydrated with ethanol $(85 \%, 90 \%, 95 \%$, and $100 \%)$ for $2 \mathrm{~min}$. All slices were placed into xylene three times, for $2 \mathrm{~min}$ per time. Subsequently, slices were immobilized by gum and dried in an incubator. Each slice was randomly observed through 6 visions by an Olympus $\mathrm{CH}-20$ optical microscope, and micrographs were obtained from Nikon-Coolpix 4500 digital camera.

2.7. DNA Condensation and Nuclear Fragmentation. Hoechst 33258 fluorescent dye was used to determine DNA condensation and nuclear fragmentation of apoptosis cells. PC12 cells were seeded in a six-well plate at a density of $2 \times 10^{5}$ cells/well. After treatment with or without ACR for $24 \mathrm{~h}$ at $37^{\circ} \mathrm{C}$, cells were washed with PBS and fixed with $4 \%$ paraformaldehyde for $20 \mathrm{~min}$ at $4^{\circ} \mathrm{C}$. The fixed cells were washed with PBS and stained with $5 \mu \mathrm{g} / \mathrm{mL}$ Hoechst 33258. After incubation for $15 \mathrm{~min}$, the cells were washed with PBS, and photos were taken under an inverted fluorescence microscope (IX71, Olympus, Japan).

2.8. Single Cell Gel Electrophoresis Assay (Comet Assay). DNA damage in the cerebellum and cortex of rats was detected by single cell gel electrophoresis (comet assay). The suitable tissues were prepared into a single cell suspension, mixed with moderate LMPA $\left(37^{\circ} \mathrm{C}\right)$, and then transferred to slides. The slides were cooled by $95 \%$ alcohol overnight, coated with NMPA, and covered with a coverslip at $4^{\circ} \mathrm{C}$ for $20 \mathrm{~min}$ at last. After the coverslip was removed, the slides were immersed in precooled cell lysate solution away from light at $4^{\circ} \mathrm{C}$ overnight. When the lysates were discarded, slides were washed three times with pure water and added with appropriate helicase fluid to unwind DNA in the dark for $20 \mathrm{~min}$. The slides were moved to the electrophoresis tank with buffer $(300 \mathrm{mmol} / \mathrm{L} \mathrm{NaOH}$ and $1 \mathrm{mmol} / \mathrm{L}$ EDTA, $\mathrm{pH}>$ 13) for $25 \mathrm{~min}$ and electrophoresis was conducted under $25 \mathrm{~V}$, $300 \mathrm{~mA}$ in the dark for $20 \mathrm{~min}$. Thereafter, samples were neutralized by buffer $(0.4 \mathrm{~mol} / \mathrm{L}$ Tris- $\mathrm{HCl}, \mathrm{pH} 7.5)$ out of light for $10 \mathrm{~min}$. Subsequently, slides were washed three times with pure water again. After air drying, samples were stained with suitable EB $(20 \mu \mathrm{g} / \mathrm{mL})$ and covered with cover slips. DNA damage was evaluated with a fluorescence system of Comet Assay Software Project (a kind of comet software, Poland). The degree of DNA damage was scored by determining the percentage of DNA in the tail as follows: tail DNA $\%=$ tail DNA/(head DNA + tail DNA) $\times 100 \%$.

2.9. Detection of Intracellular ROS Accumulation. DCFH-DA was used as a fluorescence probe to determine ROS in PC12 cells. Within the intracellular environment, DCFH-DA was deacetylated through the reaction with free radicals $\left(\mathrm{H}_{2} \mathrm{O}_{2}\right)$ and then converted into its fluorescent product DCF. PC12 cells $\left(2.5 \times 10^{5}\right.$ cells/well in a 96-well plate) were incubated at $37^{\circ} \mathrm{C}$ with $\mathrm{ACR}$ alone for $1,3,6,12$, and $24 \mathrm{~h}$, or exposed to $\operatorname{MT}(50 \mu \mathrm{mol} / \mathrm{L})$ and luzindole $(0.2 \mu \mathrm{mol} / \mathrm{L})$ at pre- $24 \mathrm{~h}$, simultaneously, and post $-3 \mathrm{~h}$ with $\mathrm{ACR}(2.5 \mathrm{mmol} / \mathrm{L})$ for $6 \mathrm{~h}$. After $30 \mathrm{~min}$ for loading probes, intoxicated-cells were washed three times with buffer. The photos of cells cotreated with ACR and MT were taken with an inverted fluorescence microscope (scale bar: $25 \mu \mathrm{m}$ ). The fluorescence intensity was examined at $\lambda \mathrm{Ex}=488 \mathrm{~nm}$ and $\lambda \mathrm{Em}=525 \mathrm{~nm}$ using a microplate reader.

2.10. Lipid Peroxidation Measurement. The MDA contents were determined by the double heating method [22], which was based on the colorimetric determination of the purple color generated by the reaction between thiobarbituric acid (TBA) and MDA. PC12 cells were incubated with ACR alone for $1,3,6,12$, and $24 \mathrm{~h}$ or treated with MT $(50 \mu \mathrm{mol} / \mathrm{L})$ and luzindole $(0.2 \mu \mathrm{mol} / \mathrm{L})$ at pre- $24 \mathrm{~h}$, simultaneously, and post$3 \mathrm{~h}$ with $\mathrm{ACR}(2.5 \mathrm{mmol} / \mathrm{L})$ for $6 \mathrm{~h}$. Culture supernatants in cells were collected by centrifugation, whereas fresh tissues of rats were homogenized in $0.9 \%$ normal saline to obtain supernatants with centrifugation. Supernatants were mixed with trichloroacetic acid (10\%, w/v) solutions, followed by $15 \mathrm{~min}$ of boiling. Samples were then centrifuged at $3000 \mathrm{rpm}$ for $10 \mathrm{~min}$, and the supernatant was transferred to new tubes to react with TBA $(0.67 \%, w / v)$ solution. After boiling for $15 \mathrm{~min}$ again, samples were cooled to room temperature, and the absorbance was determined at $532 \mathrm{~nm}$ with a microplate reader.

2.11. Antioxidants Determinations. Weighed brain tissues were homogenized in $0.9 \%$ normal saline and centrifuged at $2500 \mathrm{rpm}$ for $10 \mathrm{~min}$. The supernatants were collected for subsequent operation. The blank control, standard control, and assay group were set up. Superoxide dismutase (SOD) activity was measured based on the extent of the inhibition of amino blue tetrazolium formazan formation in the mixture of nicotinamide adenine dinucleotide, phenazine methosulfate, and nitroblue tetrazolium (NADH-PMS-NBT), according to the method described in Kakkar's study [23]. Color intensity of chromogen was determined at $560 \mathrm{~nm}$. The activity unit was defined as the number of enzymes that caused $50 \%$ inhibition of NBT reduction/mg protein. GSH content in rat cerebellum was detected using 5,5-dithiobis-2-nitrobenzoic 


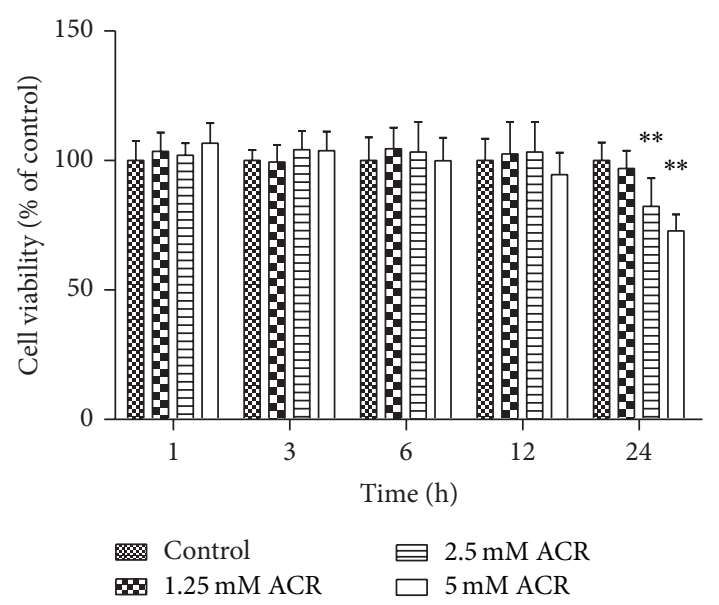

(a)

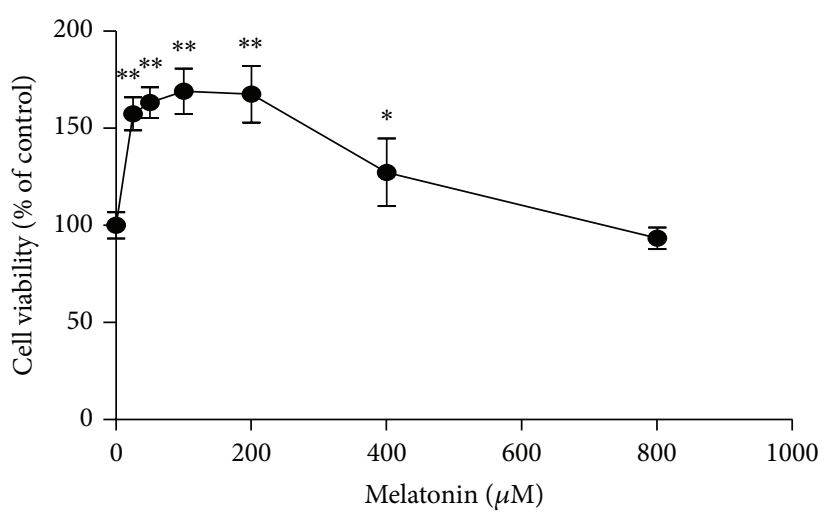

(b)

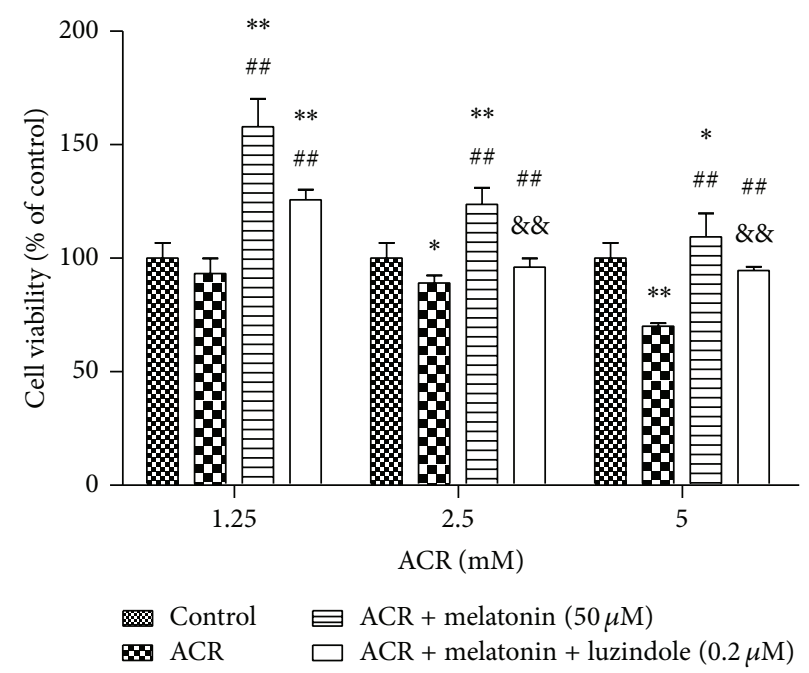

(c)

FIGURE 1: Effects of MT on cytotoxicity induced by ACR in PC12 cells. Cell viabilities were determined as relative percent of viable cells by MTT method. PC12 cells were incubated with different concentrations of ACR (1.25, 2.5, and $5 \mathrm{mM})$ for 1, 3, 6, 12, and 24 h (a) or MT (0, 25, $50,100,200,400$, and $800 \mu \mathrm{M}$ ) for $24 \mathrm{~h}$ (b). Similarly, cell viabilities were analyzed in the vehicle control group, ACR alone treatment group, $\mathrm{ACR}+\mathrm{MT}(50 \mu \mathrm{M})$ cotreatment group, and ACR $+\mathrm{MT}+$ luzindole $(0.2 \mu \mathrm{M})$ cotreatment group for $24 \mathrm{~h}(\mathrm{c})$. The results are expressed as the mean $\pm \mathrm{SD}(n=8) .{ }^{*} P<0.05,{ }^{* *} P<0.01$ versus the vehicle control group. ${ }^{\#} P<0.05,{ }^{\# *} P<0.01$ versus the ACR treatment group, ${ }^{\&} P<0.05,{ }^{\& \&} P<0.01$ versus the ACR + MT cotreatment group.

acid (DTNB) following the manufacturer's instructions. The absorbance was measured at $405 \mathrm{~nm}$ with a microplate reader. GSH-Px activity in rat cerebellum was measured by the rate of GSH consumption in unit time following the manufacturer's instructions. The absorbance was measured at a wavelength of $412 \mathrm{~nm}$.

2.12. Statistical Analysis. All results were expressed as the means \pm SD. All experiments were performed independently for at least six times. Statistical analysis was performed with SPSS18.0 software. Means were compared by one-way ANOVA, and groups were compared using the LSD method. Gait score was analyzed using the Mann-Whitney $U$ test. Statistical significance was set at $P<0.05$.

\section{Results}

3.1. MT Relieved Cytotoxicity Induced by ACR. The protective effect of MT on cytotoxicity induced by ACR in PC12 cells was observed. ACR induced a statistically significant decrease in cell viability at concentrations of 2.5 and $5 \mathrm{mmol} / \mathrm{L}$ for $24 \mathrm{~h}$ compared with the vehicle controls (Figure 1(a)). MT at a concentration range of $25 \sim 200 \mu \mathrm{mol} / \mathrm{L}$ exerted an increase effect on the decreased cell viability induced by ACR (Figure 1(b)). Cell viability significantly increased compared with the ACR treatment group when cells were cotreated with $50 \mu \mathrm{mol} / \mathrm{L} \mathrm{MT}$ and $2.5 \mathrm{mmol} / \mathrm{L} \mathrm{ACR}$ for $24 \mathrm{~h}$. Interestingly, MT receptor antagonist $(0.2 \mu \mathrm{mol} / \mathrm{L}$ luzindole $)$ inhibited the protective effect of MT on cell viability (Figure 1(c)). Hence, 


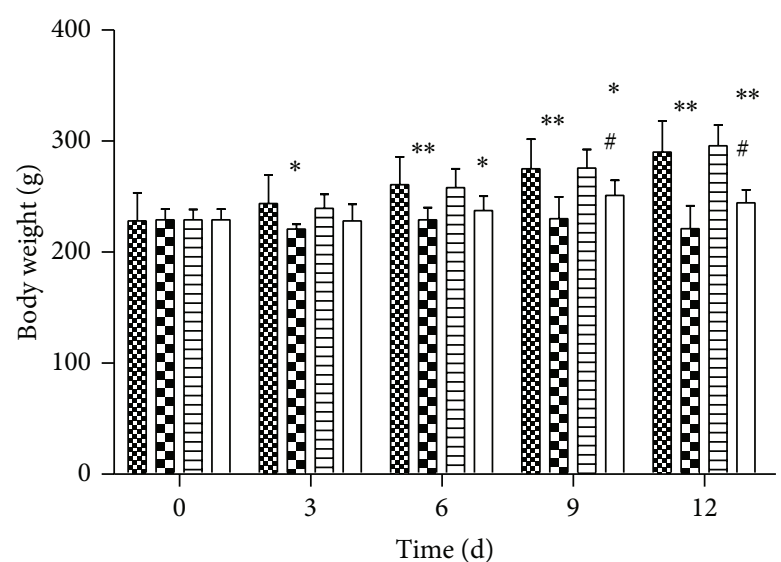

$\begin{array}{ll}\$ 8 \text { Control } & \equiv \text { Melatonin }(5 \mathrm{mg} / \mathrm{kg}) \\ \mathbf{D A C R}(40 \mathrm{mg} / \mathrm{kg}) & \square \text { ACR + melatonin }\end{array}$

(a)
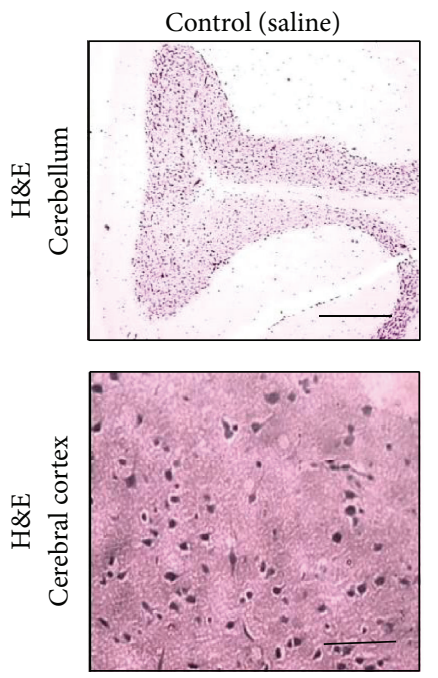

$\operatorname{ACR}(40 \mathrm{mg} / \mathrm{kg})$
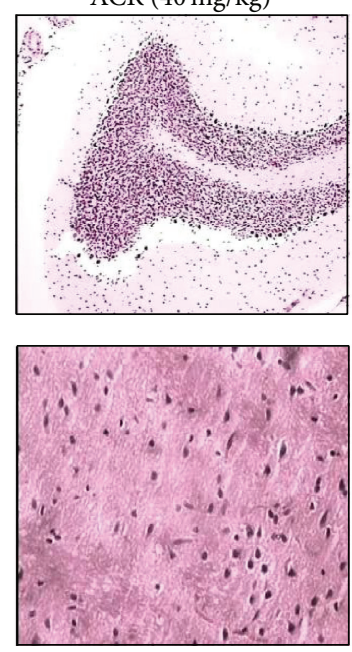

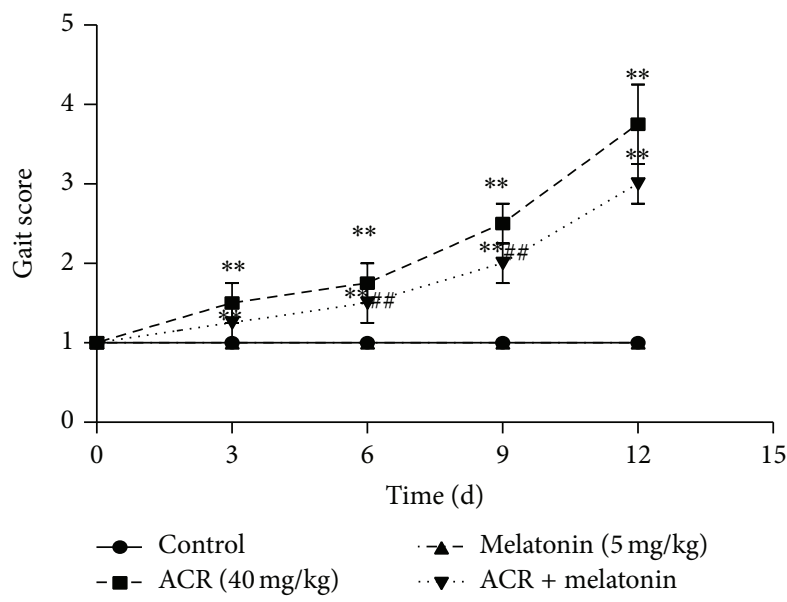

(b)
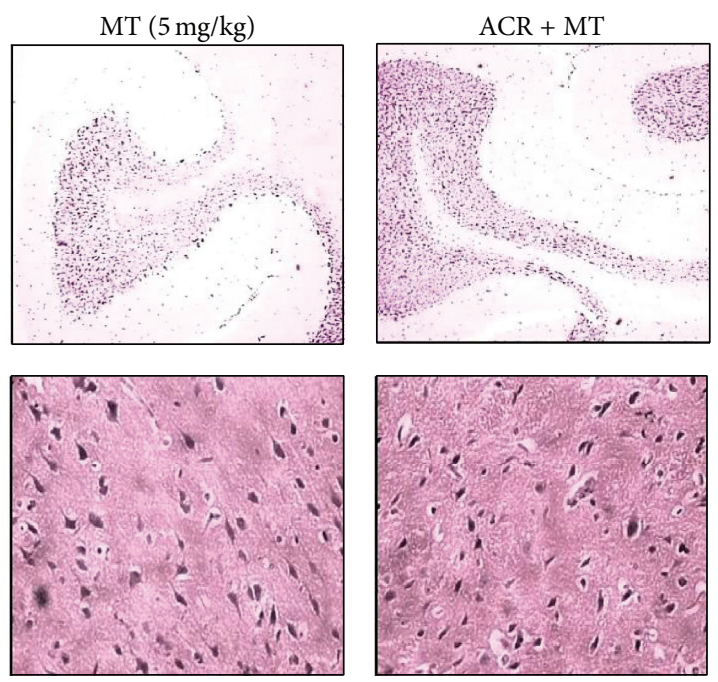

(c)

FIGURE 2: Effects of MT on behavior toxicity of rats and morphology of different brain regions. Experimental rats were divided into four groups: control (equal volume saline) group, ACR (40 mg/kg/day) treatment group, MT (5 mg/kg/day, i.p) treatment group, and ACR + MT simultaneously treatment group. Body weight (a) and gait of rats (b) were analyzed after ACR oral administration with or without MT for $0,3,6,9$, and 12 days. H\&E staining was used to observe morphological alterations of nerve cells, and the photographs were taken under a light microscope (scale bar: $100 \mu \mathrm{m})(\mathrm{c})$. The results are expressed as the mean $\pm \mathrm{SD}(n=8) .{ }^{*} P<0.05,{ }^{* *} P<0.01$ versus the vehicle control group, ${ }^{\#} P<0.05,{ }^{\# \#} P<0.01$ versus the ACR treatment group.

MT might attenuate the cytotoxicity induced by ACR in PC12 cells potentially through the MT receptor action.

3.2. MT Decreased the Behavioral Toxicity in Rats and Morphological Changes in Brain Regions. To further confirm the protective effect of MT on behavioral toxicity induced by ACR, ACR poisoning rat models were established. Body weight (Figure 2(a)) and gait (Figure 2(b)) in rats were assessed, and morphological alterations in nerve cells in different brain regions were observed by $\mathrm{H} \& \mathrm{E}$ staining with a light microscope (Figure 2(c)). The body weight of rats at $40 \mathrm{mg} / \mathrm{kg} /$ day ACR significantly decreased since the third exposure day. When rats were cotreated with $5 \mathrm{mg} / \mathrm{kg} /$ day MT (i.p) and $40 \mathrm{mg} / \mathrm{kg} /$ day ACR, the originally reduced weight caused by ACR administration showed some improvement compared with the group treated with ACR only. Similarly, gait score in the ACR group also significantly increased since the third exposure day. However, gait score in the MT intervention group significantly decreased on days 6 and 9 of ACR treatment, compared with the ACR alone group. In addition, immunohistochemical results showed that unclear cellular gradation, concentrated cell nucleus, and decreased neurons were observed in the cortex of ACR exposure, which indicated that ACR caused abnormal lesions in the cortex of rats. However, the effect of ACR on cortex neurons was not lightened by the addition of MT. Meanwhile, the increased piriform bulging neurons and the decreased grain layer neurons were observed in Purkinje cells of cerebellum 
in the ACR treatment group. When MT was added, the piriform bulging neurons were reduced and karyopyknosis were weakened in Purkinje cells. Therefore, MT relieved dyskinesia, pathological changes, and karyopyknosis induced by ACR in the cerebellum of rats.

\subsection{MT Attenuated DNA Damage Caused by ACR. DNA} damage induced by ACR and the effect of MT intervention were determined by Hoechst 33258 staining in PC12 cells and comet assay in rats (Figure 3 ). DNA condensation and fragmentation in PC12 cells treated with $2.5 \mathrm{mmol} / \mathrm{L} \mathrm{ACR}$ for $24 \mathrm{~h}$ occurred. MT at $50 \mu \mathrm{mol} / \mathrm{L}$ prevented ACR-induced morphological alterations and inhibited these apoptotic features (Figure 3(a)). In rats, a clear and reproducible DNA fragmentation was also noted in the ACR treatment group (Figure 3(b)). The statistical results in the comet assay showed the tail length, tail DNA\%, and olive tail moment (OTM) in isolated brain cells (Figures 3(c) and 3(d)). Significant increases in the tail length, tail DNA\%, and OTM values in cerebellar cells with $40 \mathrm{mg} / \mathrm{kg} /$ day ACR conditioning for 12 days were observed, as compared with the vehicle controls. After MT (i.p) at $5 \mathrm{mg} / \mathrm{kg} /$ day with ACR oral administration in rats, the tail length, tail DNA\%, and OTM significantly decreased compared with those in the ACR treatment group. However, no difference was found in the cerebral cortex. Thus, MT could protect ACR-induced DNA condensation and fragmentation.

\subsection{MT Decreased ROS Accumulation and MDA Generation} Produced by ACR in PC12 Cells. To observe the effect of MT on oxidative stress induced by ACR, ROS accumulation and MDA generation in PC12 cells were determined. ACR exposure significantly enhanced the fluorescent intensity compared with vehicle controls in PC12 cells (Figure 4(a)). The significant increases in ROS generation were found in the $1.25 \mathrm{mmol} / \mathrm{L} \mathrm{ACR} \mathrm{treatment} \mathrm{group} \mathrm{at} 3 \mathrm{~h}$, but in the 2.5 and $5 \mathrm{mmol} / \mathrm{L}$ ACR treatment groups at $1 \mathrm{~h}$ (Figure $4(\mathrm{~b})$ ). ROS levels increased in PC12 cells with ACR treatment in a concentration- and time-dependent manner. MT at $50 \mu \mathrm{mol} / \mathrm{L}$ pre- $24 \mathrm{~h}$ treatment with ACR, as well as cotreatment with ACR, protected cells from ROS accumulation induced by ACR (Figure 4(c)). MDA content at $5 \mathrm{mmol} / \mathrm{L}$ ACR treatment for $3,6,12$, and $24 \mathrm{~h}$ increased significantly (Figure 4(d)). When culture cells were pretreated with MT for $24 \mathrm{~h}$, ACR treatment for $24 \mathrm{~h}$ significantly decreased the MDA content (Figure 4(e)). Similarly, the protective effect of MT on ACR-induced ROS and MDA generation was inhibited by $0.2 \mu \mathrm{mol} / \mathrm{L}$ luzindole pretreatment for $24 \mathrm{~h}$.

3.5. MT Attenuated Oxidative Damage Induced by ACR in Rat Cerebellum. To determine the effects of MT on oxidative damage in the cerebellum of ACR $(40 \mathrm{mg} / \mathrm{kg}$ b. w/day) treatment rats for 12 days, the MDA levels were measured in the cerebellum of rats. As shown in Figure 5(a), the MDA levels significantly increased in the ACR alone treatment group, compared with those in the control group. The MDA levels markedly decreased in rats orally treated with MT ( $5 \mathrm{mg} / \mathrm{kg}$ b. w/day) intervention compared with those in the
ACR treatment group, indicating that MT inhibited MDA generation induced by ACR.

SOD activity and GSH levels were determined. As shown in Figures 5(b) and 5(c), ACR induced a significant decrease in the activities of SOD and the GSH content compared with the control group. Cerebellar SOD activity and the GSH level significantly increased in rats administered with MT compared with those in the ACR treatment group. Hence, MT exhibited the increased effects on SOD activity and GSH level in rat cerebellum. The activity of peroxide decomposition enzyme GSH-Px was also measured. As shown in Figure 5(d), GSH-Px activity significantly decreased in the ACR treatment group. However, GSH-Px activities had no significant difference between the ACR treatment group and MT (i.p) + ACR coadministration group.

\section{Discussion}

Humans are primarily exposed to ACR at low concentrations chronically through the increased intake of starchy foods. ACR has been reported to be risky for its cumulative neurotoxicity. Hence, the basic mechanisms of ACR-induced neurotoxicity on animals or humans should be illustrated. Oxidative stress is a crucial pathophysiological condition that promotes cell apoptosis and death in a broad variety of neurodegenerative disorders. Oxidative damage induced by ACR in human erythrocytes has been proposed [24]. MT, a powerful antioxidant, is likely to be protective against oxidative DNA damage induced by ACR in vitro and in vivo. However, reports on the effects of MT on ACR-induced oxidative stress are quite limited.

In the study, the differentiated PC cells induced by nerve growth factor could express neuron phenotype and characteristics and were identified to be an ideal model for studying neurotoxicity of chemicals. In cells, we focused on cell viability affected by ACR to choose the applied concentration. Cell viability in the cells treated with $2.5 \mathrm{mmol} / \mathrm{L}$ ACR for $24 \mathrm{~h}$ decreased significantly. ACR exposure exhibited obvious cytotoxicity on PC12 cells in a concentration- and time-dependent manner, whereas an increasing effect on cell viability was found with MT treatment for $24 \mathrm{~h}$. When $50 \mu \mathrm{mol} / \mathrm{L}$ MT and ACR were simultaneously added into the culture for $24 \mathrm{~h}$, cell viability significantly increased compared with that in the ACR exposure groups. Luzindole, an effective receptor antagonism, is widely used in the study of MT mechanisms [20, 25-27]. Luzindole at $0.2 \mu \mathrm{mol} / \mathrm{L}$ greatly inhibited the increase effect of MT on cell viability, which indicated that the receptor pathway played a vital role in the effects of MT on oxidative damage. Similarly, DNA condensation and fragmentation caused by ACR by Hoechst staining assay were observed by Hoechst staining assay, and MT co-conditioning decreased DNA fragmentation induced by ACR. MT exerted a good protective effect on ACR-induced cytotoxicity through the MT receptor pathway.

The delicate balance between the generation and catabolism of oxidants is critical for the maintenance of biological function [28]. Results demonstrated that ROS production in PC12 cells increased significantly after exposure to ACR, consistent with the results in 

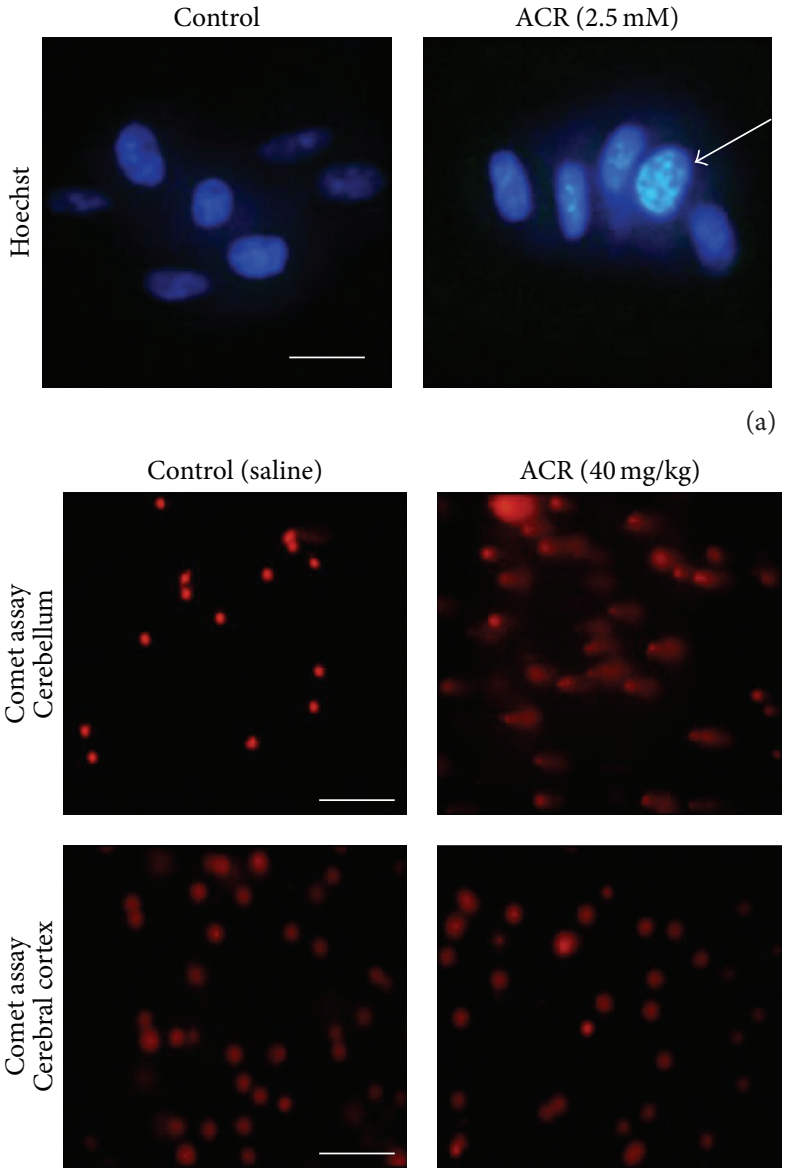

(b)

(a)

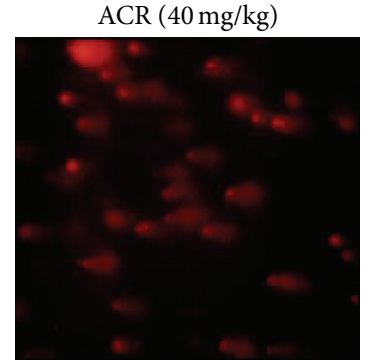

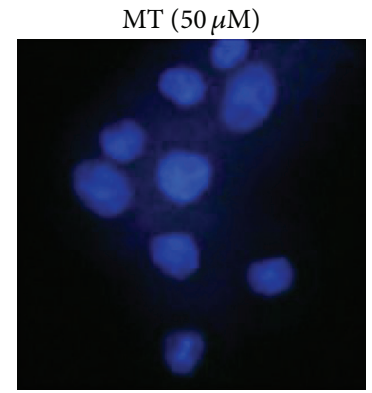
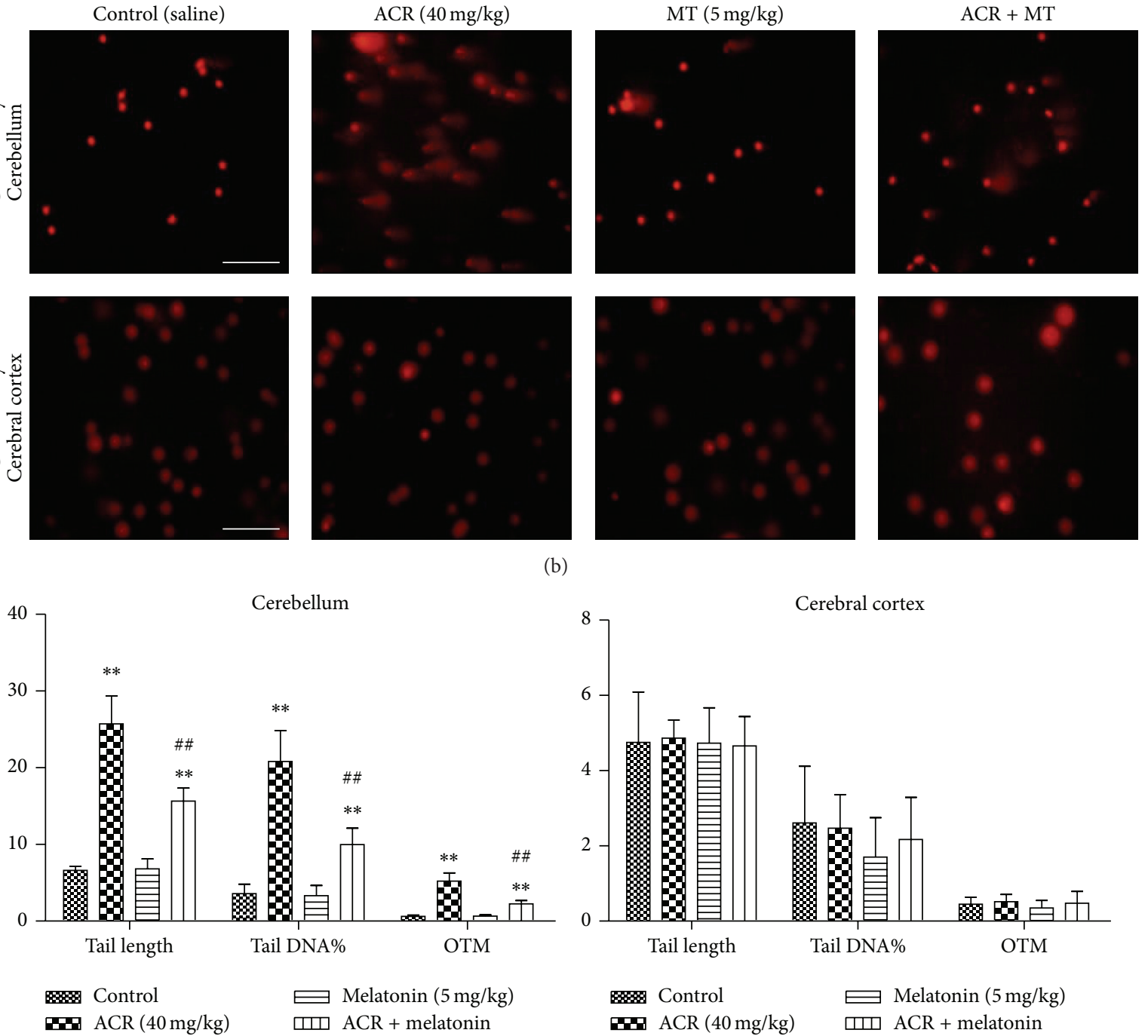

(c)

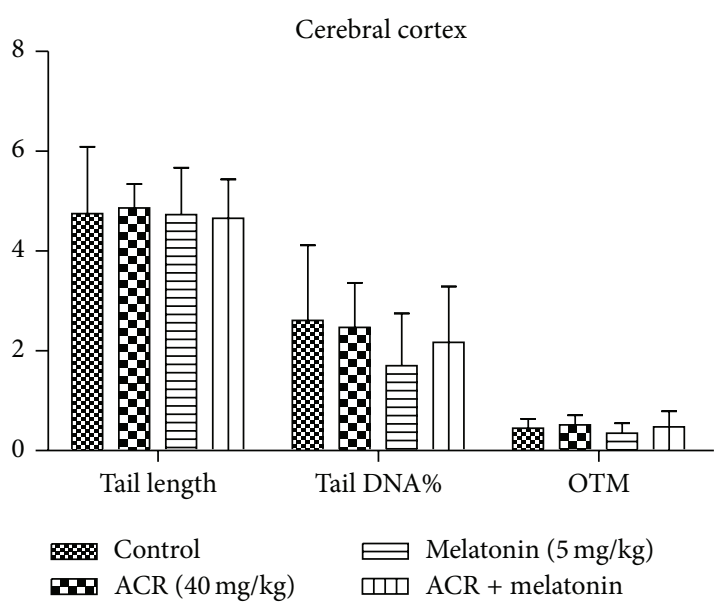

(d)

FIGURE 3: Effect of MT on ACR-induced DNA damage in PC12 cells and in rats. PC12 cells were cultured with vehicle controls, ACR (2.5 mM), MT $(50 \mu \mathrm{M})$, or ACR + MT cotreatment for $24 \mathrm{~h}$. DNA condensation in cells was investigated using Hoechst 33258 nuclear staining with an inverted fluorescent microscope (scale bar: $25 \mu \mathrm{m}$ ) (a). Arrows in photos refer to the positive cells. Experimental rats were divided into four groups: control (equal volume normal saline) group, ACR $(40 \mathrm{mg} \cdot \mathrm{kg} /$ day) treatment group, MT (5 mg/kg/day, i.p) treatment group, and ACR + MT simultaneously treatment group. The features of DNA damage were exhibited by a comet assay (scale bar: $50 \mu \mathrm{m})(\mathrm{b})$. Tail length, tail DNA\%, and olive tail-moment (OTM) were statistically analyzed to assess the degree of DNA damage in rat cerebellum (c) and cerebral cortex $(\mathrm{d})$. The results are expressed as the mean $\pm \operatorname{SD}(n=6) .{ }^{*} P<0.05,{ }^{* *} P<0.01$ versus the vehicle control group, ${ }^{\#} P<0.05,{ }^{\# \#} P<0.01$ versus the ACR treatment group. 

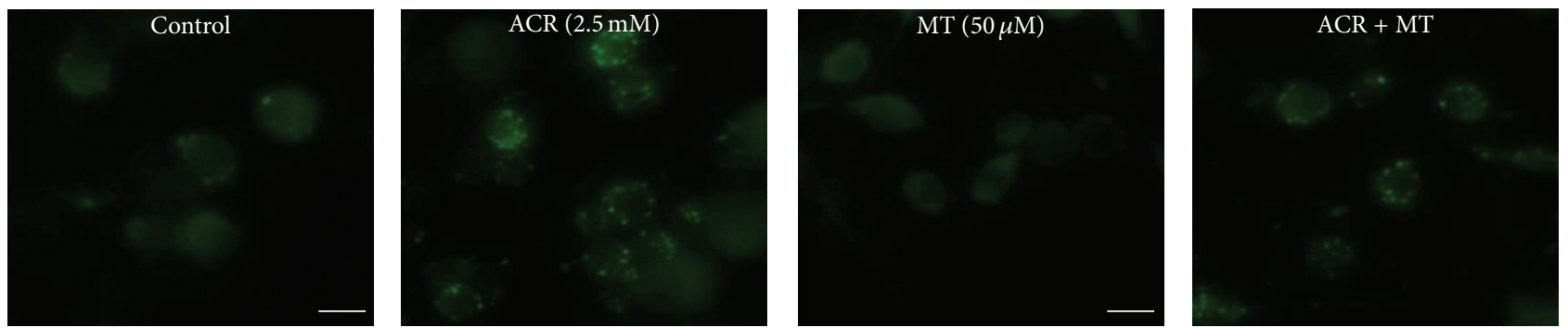

(a)

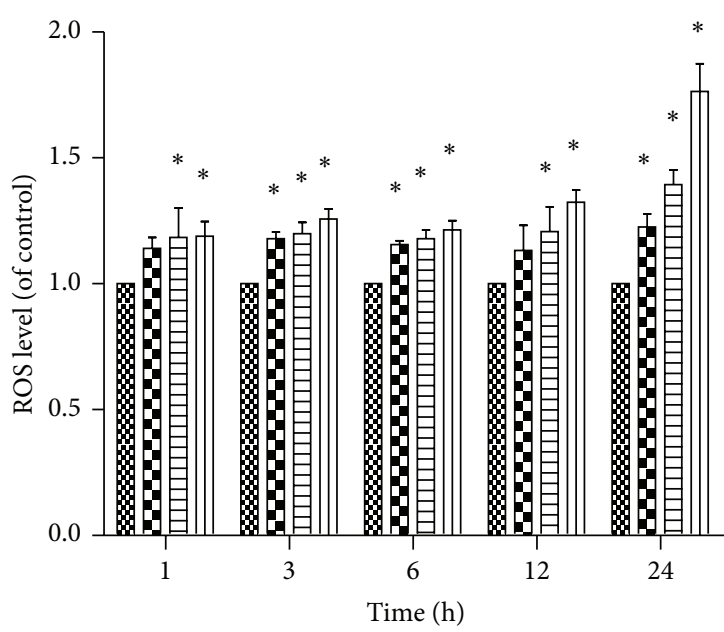

*a Control

$1.25 \mathrm{mM}$

戸 $2.5 \mathrm{mM}$

Ш $5 \mathrm{mM}$

(b)

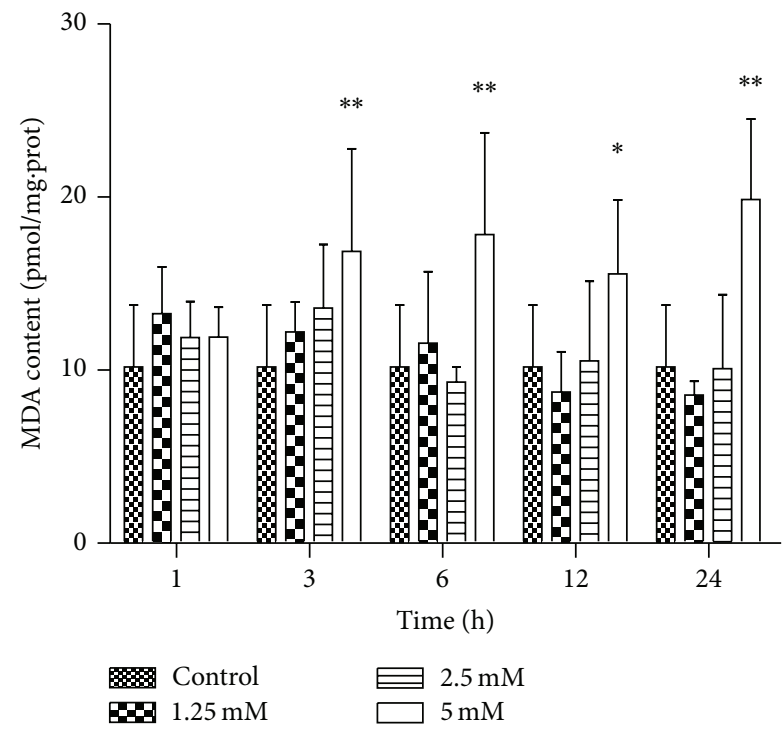

(d)

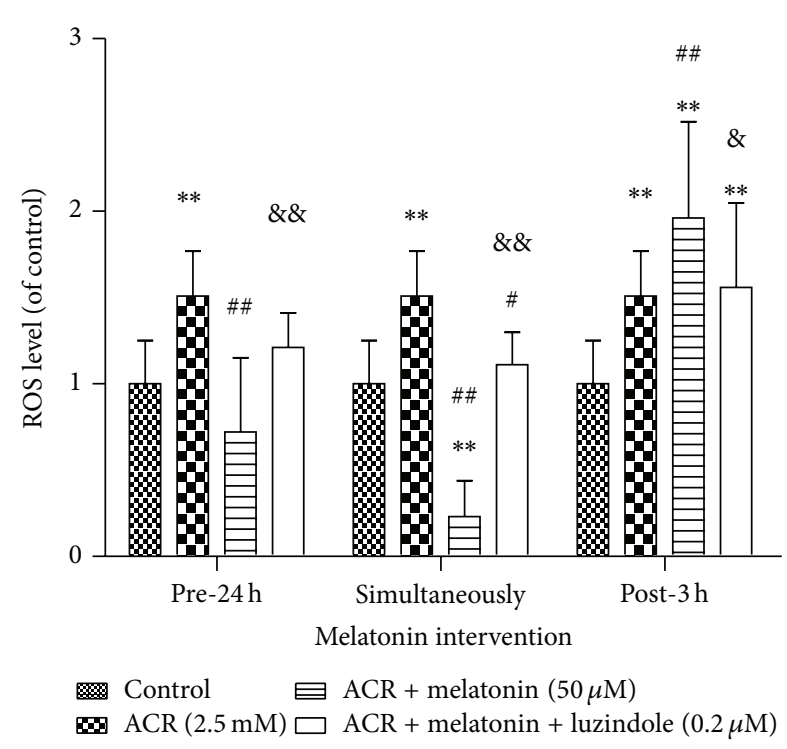

(c)

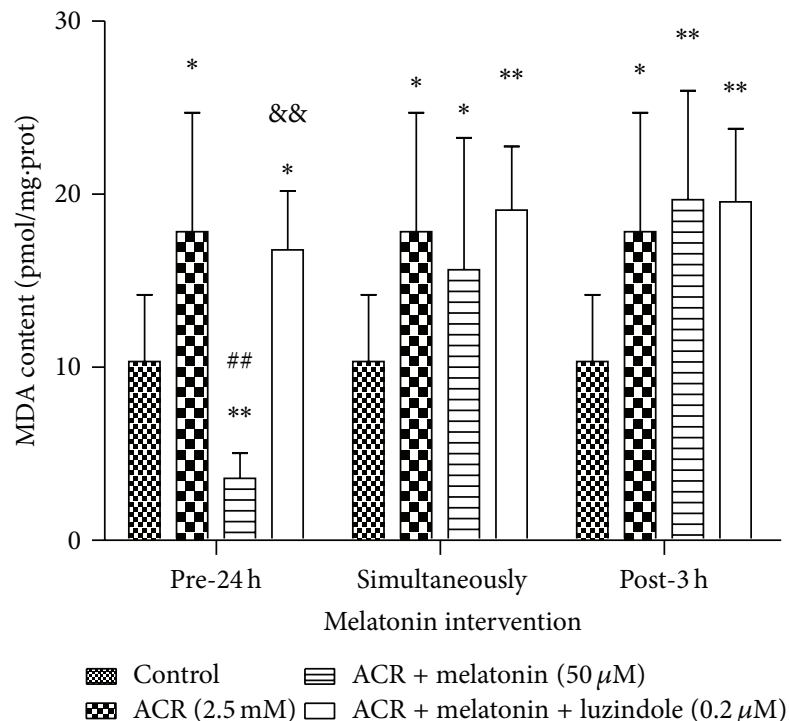

(e)

FIGURE 4: Effects of MT on ROS and MDA generations induced by ACR in PC12 cells. Intracellular ROS was evaluated by DCFH-DA detection. Fluorescent photographs were shown after exposure to ACR with or without MT cotreatment for $24 \mathrm{~h}$ (scale bar: $25 \mu \mathrm{m})(\mathrm{a})$. In addition, ROS (b) and MDA (d) productions induced by treatment with $\operatorname{ACR}(1.25,2.5$, and $5 \mathrm{mM})$ alone for 1, 3, 6, 12, and $24 \mathrm{~h}$. Moreover, MT $(50 \mu \mathrm{M})$ and luzindole $(0.2 \mu \mathrm{M})$ interventions at different times: $24 \mathrm{~h}$ pretreatment, simultaneously, and $3 \mathrm{~h}$ posttreatment with ACR $(2.5 \mathrm{mM})$ for $6 \mathrm{~h}$ were designed $((\mathrm{c})$ and $(\mathrm{e}))$. The results are expressed as the mean $\pm \mathrm{SD}(n=8) .{ }^{*} P<0.05,{ }^{* *} P<0.01$ versus the vehicle control group. ${ }^{\#} P<0.05,{ }^{\# \#} P<0.01$ versus the ACR treatment group, ${ }^{8} P<0.05,{ }^{8 \&} P<0.01$ versus the ACR + MT cotreatment group. 


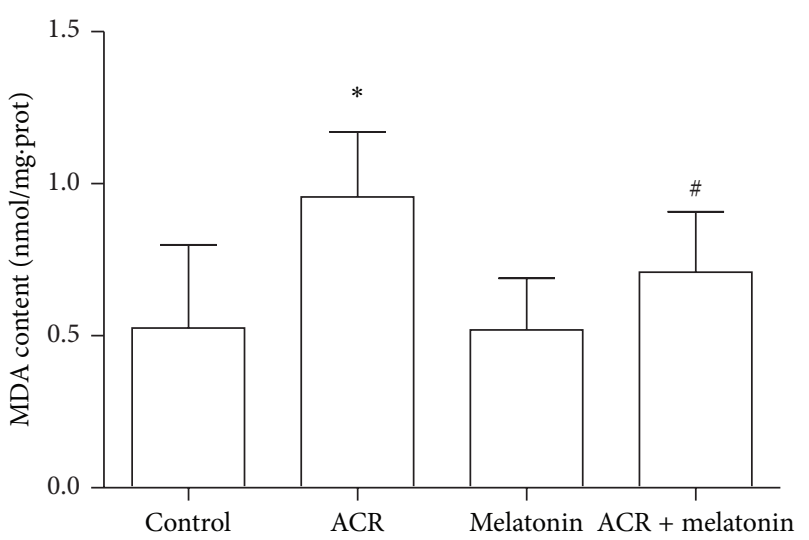

(a)

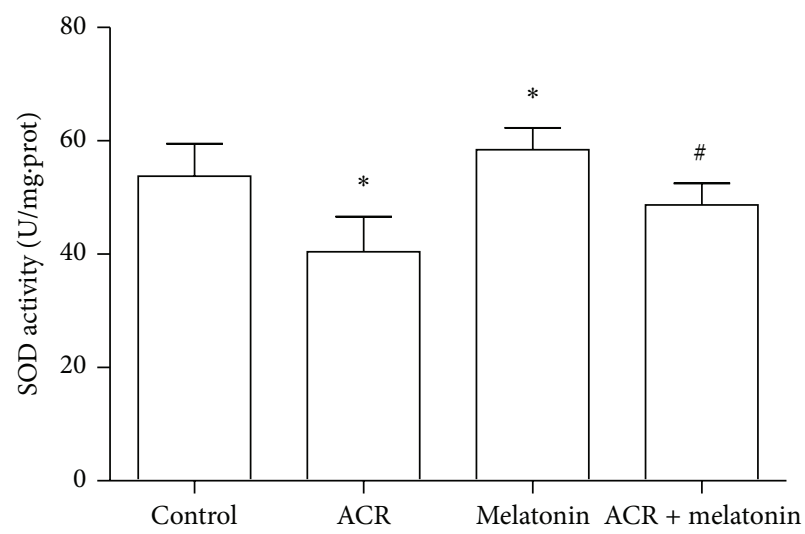

(c)

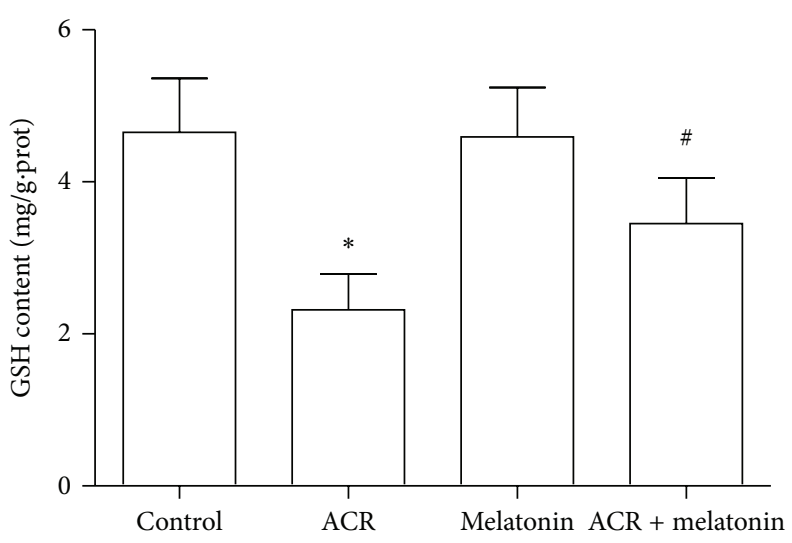

(b)

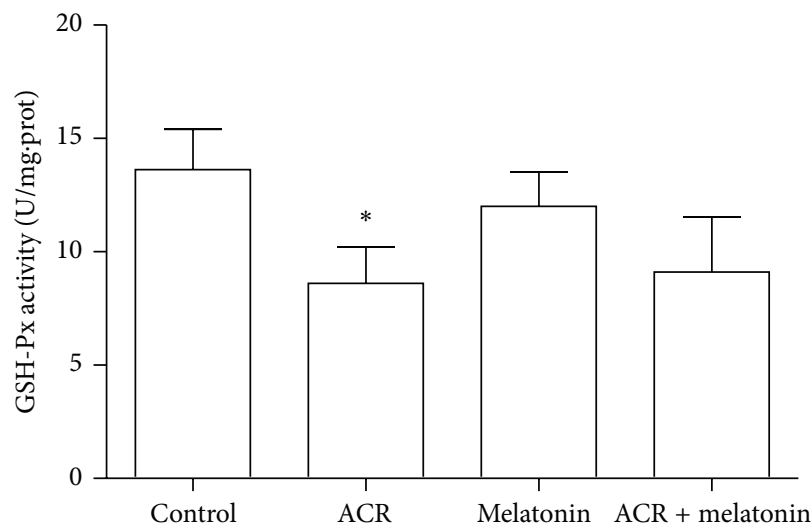

(d)

Figure 5: Effects of MT on MDA generation, GSH depletion, and SOD and GSH-Px activities caused by ACR in rat cerebellum. Experimental animals were divided into four groups: control (equal volume saline) group, ACR ( $40 \mathrm{mg} / \mathrm{kg} / \mathrm{day}$ ) treatment group, MT (5 mg/kg/day) treatment group, and ACR + MT cotreatment group. Following oral exposure for 12 days, MDA level (a), GSH content (b), SOD (c), and GSH-Px (d) activities were determined by the colorimetric method with a microplate reader. The results are expressed as the mean \pm SD $(n=8) .{ }^{*} P<0.05,{ }^{* *} P<0.01$ versus the vehicle control group, ${ }^{\#} P<0.05,{ }^{\# \#} P<0.01$ versus the ACR treatment group.

previous studies $[8,29]$. When the cells underwent MT preconditioning for $24 \mathrm{~h}$ or cotreatment with ACR, the decreased level of intracellular ROS was superior to that with MT posttreatment for $3 \mathrm{~h}$. MDA is a decomposition product that has been used as a biomarker of lipid peroxidation for many years [30]. The MDA level was found to increase after ACR treatment alone for $3 \mathrm{~h}$. This result was consistent with previous studies, where an increase in free radicals causes overproduction of MDA [11]. Therefore, MT pretreatment for $24 \mathrm{~h}$ prevented the development of lipid peroxidation. Interestingly, we observed that a significant increase in ROS and MDA levels induced by ACR was inhibited by receptor antagonist luzindole, indicating that luzindole exerted its channel blocking inhibitory action, and the protective effect of MT might be due to action of the MT receptors. As far as we know, MT can exert the antioxidant action mainly by membrane receptors and nuclear receptors to induce the expression of antioxidant enzymes and its ability to directly scavenge free radicals. However, in our present study, luzindole was used to test if melatonin receptor played a role in melatonin action. The results showed that blocking the receptors could not completely inhibit the protective effect of MT, surely signifying that other nonreceptor pathways might be involved in the MT activity. It was reported that MT could induce neuroprotection after focal cerebral ischemia in mice by signal pathways [21]. MT could also regulate neurodegeneration through energy metabolism and epigenetic processes in neuronal cells [31]. It was very interesting and necessary to make further researches on the mechanism of melatonin neuroprotection against ACR.

The results in cells confirmed that MT was an effective antioxidant and exerted an antagonized effect on free radicals and other oxidative products generation. To further verify the protective effect of MT on oxidative damage induced by ACR, we attempted to apply MT to observe behavioral toxicity induced by ACR to determine the used dosage. In our preliminary experiments, ACR treatment at $40 \mathrm{mg} / \mathrm{kg} / \mathrm{day}$ for 12 days induced obvious neuropathy in rats, resulting in motor dysfunction and coordination impairment, in accordance with the previous studies $[10,32]$. ACR is known to 
affect both the central and peripheral nervous systems in laboratory animals and humans. Hence, the gait response was considered to be the representatives of the peripheral nervous system of rats. Gait observations are a relatively sensitive parameter to evaluate neurological changes during exposure of rats to specific chemicals [33]. Consistent with our hypothesis, $40 \mathrm{mg} / \mathrm{kg} /$ day ACR subacute exposure caused weight loss of rats and motor impairment in rats. Weight loss of rats might be caused by the decreased amount of food intake or low efficiency, which was calculated by body weight gain per $100 \mathrm{~g}$ of food intake. Statistically significant gait changes in the presence of ACR for 3 days occurred. Results showed that MT relieved gait abnormality at 6 days and reduced the extent of weight loss at 9 days. Ataxia, an abnormality in the fine control of movement, is most commonly due to dysfunction of the cerebellum [34]. Hence, we observed pathological alterations in Purkinje cells and nuclear condensation in the cerebellum of rats, whereas no changes were observed in the cerebral cortex of rats. MT intervention restored the cerebellum lesions. This result might explain gait abnormality induced by ACR.

In previous studies in vitro, ROS levels showed a significant increase in the presence of ACR. DNA is sensitive for ROS generation induced by toxic chemicals. When ROS production and the scavenging system lose balance, excessive ROS can attack DNA macromolecules, causing oxidative DNA damage [35]. The single cell gel electrophoresis technique is a sensitive and useful for detecting DNA damage and repair in single cells [36]. Some studies showed that ACR exposure caused a significant increase in DNA migration in vitro and in vivo [37-39]. The comet assay showed that ACR administration led to apparent DNA fragmentation in the cerebellum cells, indicating that ACR had potential genotoxicity to animals after subacute exposure. MT with ACR coadministration repaired oxidative DNA damage, which revealed that MT could be used as an alternative and effective treatment as described in Ferreira's study [40]. Moreover, a significant increase in MDA level was observed in the cerebellum, suggesting the enhancement of lipid peroxidation. The results were consistent with those in PC12 cells, showing that MT exerted antioxidant action by decreasing lipid peroxidative product MDA levels in this study. When MT (i.p) with ACR cotreatment was applied, MDA products were significantly inhibited and almost recovered to the control values. Oxidative stress is usually considered as an imbalance between oxidation system and antioxidant system. ROS generation is efficiently scavenged by enzymatic antioxidant system (such as SOD and GSH-Px) and nonenzymatic antioxidants (such as GSH). SOD plays a pivotal role in the ROS defense system. Charged amino acid residues surround the center of the positively charged SOD, which creates an electric field gradient that directs $\mathrm{O}_{2}{ }^{--}$into the center of the active enzyme through a mechanism called electrostatic guidance $[41,42]$. In this study, SOD and GSHPx activities decreased markedly in the cerebellum after 12 days of ACR treatment, leading to decrease of antioxidative function. Cotreatment with MT and ACR alleviated the decrease in SOD and GSH-Px activities. GSH, which can effectively scavenge free radicals directly and indirectly, is a major nonenzymatic antioxidant. GSH deficiency contributes to oxidative stress, which takes effect in the pathogenesis of many diseases, such as Alzheimer's disease [43]. Previous studies showed that conjugation with glutathione (GSH) was a mechanism for the detoxification of $\operatorname{ACR}[44,45]$. The results demonstrated that ACR administration caused the decrease in GSH in the cerebellum. GSH depletion might make the cerebellum more sensitive to oxidative stress. In this study, cotreatment with MT and ACR effectively prevented GSH depletion exposed to ACR for 12 days. Notably, GSH levels in the cerebellum cotreated with MT were recovered. This result was consistent with the effects of some polyphenols and antioxidants, such as curcumin, hydroxytyrosol, and tea polyphenols, on the GSH depletion in previous studies [46-50]. We infer that the protective effect of MT might be directly related to eliminating free radicals or lipid peroxide and increasing antioxidant enzymes activities through the major intracellular signal pathways. However, the specific mechanisms require further study.

\section{Conclusions}

In conclusion, our study suggested that oxidative damage induced by ACR was inhibited by MT both in vitro and in vivo. MT treatment prevented DNA fragmentation, as well as ROS and MDA overproduction induced by ACR, in PC12 cells. In rat cerebellum, MT could not only alleviate nucleus concentration and DNA damage, but also inhibit the increase in MDA levels, the decrease in SOD and GSH-Px activities, and nonenzymatic antioxidant GSH depletion caused by ACR exposure. Hence, MT is effective in preventing ACRinduced oxidative damage, which provides a good basis for beneficial applications in the chemoprevention of ACR toxicity.

\section{Abbreviations}

$\begin{array}{ll}\text { ACR: } & \text { Acrylamide } \\ \text { MT: } & \text { Melatonin } \\ \text { ROS: } & \text { Reactive oxygen species } \\ \text { MDA: } & \text { Malondialdehyde } \\ \text { SOD: } & \text { Superoxide dismutase } \\ \text { GSH: } & \text { Glutathione } \\ \text { GSH-Px: } & \text { Glutathione peroxidase } \\ \text { FBS: } & \text { Fetal bovine serum }\end{array}$

DCFH-DA: 2,7-Dichlorofluorescein diacetate

MTT: 3-(4,5-Dimethylthiazol-2-yl)-2,5-

diphenyltetrazolium

TBA: Thiobarbituric acid

TCA: Trichloroacetic acid

EB: $\quad$ Ethidium bromide

DMSO: Dimethyl sulfoxide

LMPA: Low-melting-point agarose

NMPA: Normal-melting-point agarose

DTNB: 5,5-Dithiobis-2-nitrobenzoic acid

NADH: Nicotinamide adenine dinucleotide

PMS: $\quad$ Phenazine methosulfate

NBT: Nitroblue tetrazolium. 


\section{Conflict of Interests}

The authors declare that there is no conflict of interests regarding the publication of this paper.

\section{Acknowledgments}

The authors appreciate all the members participating in this study. This work was financially supported by the National Natural Science Foundation of China (no. 81373042) and the Independent Innovation Foundation of Huazhong University of Science and Technology (no. 2013TS003).

\section{References}

[1] D. R. Lineback, J. R. Coughlin, and R. H. Stadler, "Acrylamide in foods: a review of the science and future considerations," Annual Review of Food Science and Technology, vol. 3, no. 1, pp. 15-35, 2012.

[2] D. Sharp, "Acrylamide in food," The Lancet, vol. 361, no. 9355, pp. 361-362, 2003.

[3] P. Erkekoglu and T. Baydar, "Acrylamide neurotoxicity," Nutritional Neuroscience, vol. 17, no. 2, pp. 49-57, 2014.

[4] A. Allam, A. A. El-Ghareeb, M. Abdul-Hamid, A. Baikry, and M. I. Sabri, "Prenatal and perinatal acrylamide disrupts the development of cerebellum in rat: biochemical and morphological studies," Toxicology and Industrial Health, vol. 27, no. 4, pp. 291-306, 2011.

[5] P. S. Spencer and H. H. Schaumburg, "A review of acrylamide neurotoxicity. Part I. Properties, uses and human exposure," The Canadian Journal of Neurological Sciences, vol. 1, no. 2, pp. $143-$ 150, 1974.

[6] P. S. Spencer and H. H. Schaumburg, "A review of acrylamide neurotoxicity. Part II. Experimental animal neurotoxicity and pathologic mechanisms," The Canadian Journal of Neurological Sciences, vol. 1, no. 3, pp. 152-169, 1974.

[7] S. N. Prasad and Muralidhara, "Evidence of acrylamide induced oxidative stress and neurotoxicity in Drosophila melanogasterits amelioration with spice active enrichment: relevance to neuropathy," NeuroToxicology, vol. 33, no. 5, pp. 1254-1264, 2012.

[8] J. Song, M. Zhao, X. Liu, Y. Zhu, X. Hu, and F. Chen, "Protection of cyanidin-3-glucoside against oxidative stress induced by acrylamide in human MDA-MB-231 cells," Food and Chemical Toxicology, vol. 58, pp. 306-310, 2013.

[9] M. I. Yousef and F. M. El-Demerdash, "Acrylamide-induced oxidative stress and biochemical perturbations in rats," Toxicology, vol. 219, no. 1-3, pp. 133-141, 2006.

[10] Y.-J. Zhu, T. Zeng, Y.-B. Zhu et al., "Effects of acrylamide on the nervous tissue antioxidant system and sciatic nerve electrophysiology in the rat," Neurochemical Research, vol. 33, no. 11, pp. 2310-2317, 2008.

[11] S. Cuzzocrea and R. J. Reiter, "Pharmacological action of melatonin in shock, inflammation and ischemia/reperfusion injury," European Journal of Pharmacology, vol. 426, no. 1-2, pp. $1-10,2001$.

[12] A. Dominguez-Rodriguez and P. Abreu-Gonzalez, "Melatonin: still a forgotten antioxidant," International Journal of Cardiology, vol. 149, no. 3, p. 382, 2011.
[13] J. Bai, L. Dong, Z. Song et al., "The role of melatonin as an antioxidant in human lens epithelial cells," Free Radical Research, vol. 47, no. 8, pp. 635-642, 2013.

[14] I. Crespo, B. S. Miguel, A. Laliena et al., "Melatonin prevents the decreased activity of antioxidant enzymes and activates nuclear erythroid 2-related factor 2 signaling in an animal model of fulminant hepatic failure of viral origin," Journal of Pineal Research, vol. 49, no. 2, pp. 193-200, 2010.

[15] R. J. Reiter, D.-X. Tan, S. Rosales-Corral, and L. C. Manchester, "The universal nature, unequal distribution and antioxidant functions of melatonin and its derivatives," Mini-Reviews in Medicinal Chemistry, vol. 13, no. 3, pp. 373-384, 2013.

[16] H. Tamura, A. Takasaki, T. Taketani et al., "The role of melatonin as an antioxidant in the follicle," Journal of Ovarian Research, vol. 5, no. 1, article 5, 2012.

[17] G. Di Bella, F. Mascia, L. Gualano, and L. Di Bella, "Melatonin anticancer effects: review," International Journal of Molecular Sciences, vol. 14, no. 2, pp. 2410-2430, 2013.

[18] I. F. Tresguerres, F. Tamimi, H. Eimar et al., "Melatonin dietary supplement as an anti-aging therapy for age-related bone loss," Rejuvenation Research, vol. 17, no. 4, pp. 341-346, 2014.

[19] J. B. Fourtillan, A. M. Brisson, P. Gobin, I. Ingrand, J. P. Decourt, and J. Girault, "Bioavailability of melatonin in humans after daytime administration of D7 melatonin," Biopharmaceutics and Drug Disposition, vol. 21, no. 1, pp. 15-22, 2000.

[20] A. M. Mathes, B. Wolf, and H. Rensing, "Melatonin receptor antagonist luzindole is a powerful radical scavenger in vitro," Journal of Pineal Research, vol. 45, no. 3, pp. 337-338, 2008.

[21] Ü. Kilic, E. Kilic, R. J. Reiter, C. L. Bassetti, and D. M. Hermann, "Signal transduction pathways involved in melatonin-induced neuroprotection after focal cerebral ischemia in mice," Journal of Pineal Research, vol. 38, no. 1, pp. 67-71, 2005.

[22] H. H. Draper and M. Hadley, "Malondialdehyde determination as index of lipid peroxidation," Methods in Enzymology, vol. 186, pp. 421-431, 1990.

[23] P. Kakkar, B. Das, and P. N. Viswanathan, "A modified spectrophotometric assay of superoxide dismutase," Indian Journal of Biochemistry \& Biophysics, vol. 21, no. 2, pp. 130-132, 1984.

[24] B. Catalgol, G. Özhan, and B. Alpertunga, "Acrylamide-induced oxidative stress in human erythrocytes," Human \& Experimental Toxicology, vol. 28, no. 10, pp. 611-617, 2009.

[25] D. L. Drazen, D. Bilu, S. D. Bilbo, and R. J. Nelson, "Melatonin enhancement of splenocyte proliferation is attenuated by luzindole, a melatonin receptor antagonist," American Journal of Physiology-Regulatory, Integrative and Comparative Physiology, vol. 280, no. 5, pp. R1476-R1482, 2001.

[26] U. M. Umit, T. Berna, K. Handan et al., "Role of melatonin and luzindole in rat mammary cancer," Journal of Investigative Surgery, vol. 25, no. 6, pp. 345-353, 2012.

[27] M.-O. Zhou, S. Jiao, Z. Liu, Z.-H. Zhang, and Y.-A. Mei, "Luzindole, a melatonin receptor antagonist, inhibits the transient outward $\mathrm{K}^{+}$current in rat cerebellar granule cells," Brain Research, vol. 970, no. 1-2, pp. 169-177, 2003.

[28] B. Sridevi, K. V. Reddy, and S. L. N. Reddy, "Effect of trivalent and hexavalent chromium on antioxidant enzyme activities and lipid peroxidation in a freshwater field crab, Barytelphusa guerini," Bulletin of Environmental Contamination and Toxicology, vol. 61, no. 3, pp. 384-390, 1998.

[29] J.-H. Chen, C.-H. Yang, Y.-S. Wang, J.-G. Lee, C.-H. Cheng, and C.-C. Chou, "Acrylamide-induced mitochondria collapse and apoptosis in human astrocytoma cells," Food and Chemical Toxicology, vol. 51, no. 1, pp. 446-452, 2013. 
[30] J. Lykkesfeldt, "Malondialdehyde as biomarker of oxidative damage to lipids caused by smoking," Clinica Chimica Acta, vol. 380, no. 1-2, pp. 50-58, 2007.

[31] A. Jenwitheesuk, C. Nopparat, S. Mukda, P. Wongchitrat, and P. Govitrapong, "Melatonin regulates aging and neurodegeneration through energy metabolism, epigenetics, autophagy and circadian rhythm pathways," International Journal of Molecular Sciences, vol. 15, no. 9, pp. 16848-16884, 2014.

[32] S. M. Seale, Q. Feng, A. K. Agarwal, and A. T. El-Alfy, "Neurobehavioral and transcriptional effects of acrylamide in juvenile rats," Pharmacology Biochemistry and Behavior, vol. 101, no. 1, pp. 77-84, 2012.

[33] R. M. LoPachin, J. F. Ross, M. L. Reid, S. Das, S. Mansukhani, and E. J. Lehning, "Neurological evaluation of toxic axonopathies in rats: acrylamide and 2,5-hexanedione," NeuroToxicology, vol. 23, no. 1, pp. 95-110, 2002.

[34] D. J. Bonthius, "Ataxia and the cerebellum," Seminars in Pediatric Neurology, vol. 18, no. 2, pp. 69-71, 2011.

[35] W. Łuczaj and E. Skrzydlewska, "DNA damage caused by lipid peroxidation products," Cellular \& Molecular Biology Letters, vol. 8, no. 2, pp. 391-413, 2003.

[36] N. P. Singh, M. T. McCoy, R. R. Tice, and E. L. Schneider, "A simple technique for quantitation of low levels of DNA damage in individual cells," Experimental Cell Research, vol. 175, no. 1, pp. 184-191, 1988.

[37] J.-H. Chen, T.-C. Tsou, I.-M. Chiu, and C.-C. Chou, "Proliferation inhibition, DNA damage, and cell-cycle arrest of human astrocytoma cells after acrylamide exposure," Chemical Research in Toxicology, vol. 23, no. 9, pp. 1449-1458, 2010.

[38] H. Ma, W. Wang, Y. Yang, and H. Cui, "Studies on DNA damage and repair induced by acrylamide in cells from mouse various organs," Journal of Hygiene Research, vol. 37, no. 5, pp. 612-614, 2008.

[39] I. Manière, T. Godard, D. R. Doerge et al., "DNA damage and DNA adduct formation in rat tissues following oral administration of acrylamide," Mutation Research-Genetic Toxicology and Environmental Mutagenesis, vol. 580, no. 1-2, pp. 119-129, 2005.

[40] S. G. Ferreira, R. A. Peliciari-Garcia, S. A. Takahashi-Hyodo et al., "Effects of melatonin on DNA damage induced by cyclophosphamide in rats," Brazilian Journal of Medical and Biological Research, vol. 46, no. 3, 2013.

[41] V. J.-P. Lévêque, C. K. Vance, H. S. Nick, and D. N. Silverman, "Redox properties of human manganese superoxide dismutase and active-site mutants," Biochemistry, vol. 40, no. 35, pp.1058610591, 2001

[42] K. Pawłowska-Góral, E. Kurzeja, and M. Stec, "N-acetylcysteine protects against fluoride-induced oxidative damage in primary rat hepatocytes," Toxicology in Vitro, vol. 27, no. 8, pp. 22792282, 2013.

[43] G. Wu, Y.-Z. Fang, S. Yang, J. R. Lupton, and N. D. Turner, "Glutathione metabolism and its implications for health," Journal of Nutrition, vol. 134, no. 3, pp. 489-492, 2004.

[44] C. M. Beiswanger, R. D. Mandella, T. R. Graessle, K. R. Reuhl, and H. E. Lowndes, "Synergistic neurotoxic effects of styrene oxide and acrylamide: glutathione-independent necrosis of cerebellar granule cells," Toxicology and Applied Pharmacology, vol. 118, no. 2, pp. 233-244, 1993.

[45] G. C. Tong, W. K. Cornwell, and G. E. Means, "Reactions of acrylamide with glutathione and serum albumin," Toxicology Letters, vol. 147, no. 2, pp. 127-131, 2004.
[46] J. Cao, Y. Liu, L. Jia et al., "Curcumin attenuates acrylamideinduced cytotoxicity and genotoxicity in HepG2 cells by ROS scavenging," Journal of Agricultural and Food Chemistry, vol. 56, no. 24, pp. 12059-12063, 2008.

[47] I. Rodríguez-Ramiro, M. Á. Martín, S. Ramos, L. Bravo, and L. Goya, "Olive oil hydroxytyrosol reduces toxicity evoked by acrylamide in human Caco-2 cells by preventing oxidative stress," Toxicology, vol. 288, no. 1-3, pp. 43-48, 2011.

[48] I. Rodríguez-Ramiro, S. Ramos, L. Bravo, L. Goya, and M. Á. Martín, "Procyanidin B2 and a cocoa polyphenolic extract inhibit acrylamide-induced apoptosis in human Caco-2 cells by preventing oxidative stress and activation of JNK pathway," Journal of Nutritional Biochemistry, vol. 22, no. 12, pp. 1186-1194, 2011.

[49] Q. Xie, Y. Liu, H. Sun et al., "Inhibition of acrylamide toxicity in mice by three dietary constituents," Journal of Agricultural and Food Chemistry, vol. 56, no. 15, pp. 6054-6060, 2008.

[50] X. Zhang, J. Cao, L. Jiang, C. Geng, and L. Zhong, "Protective effect of hydroxytyrosol against acrylamide-induced cytotoxicity and DNA damage in HepG2 cells," Mutation Research/Fundamental and Molecular Mechanisms of Mutagenesis, vol. 664, no. 1-2, pp. 64-68, 2009. 


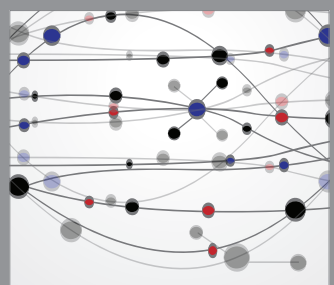

The Scientific World Journal
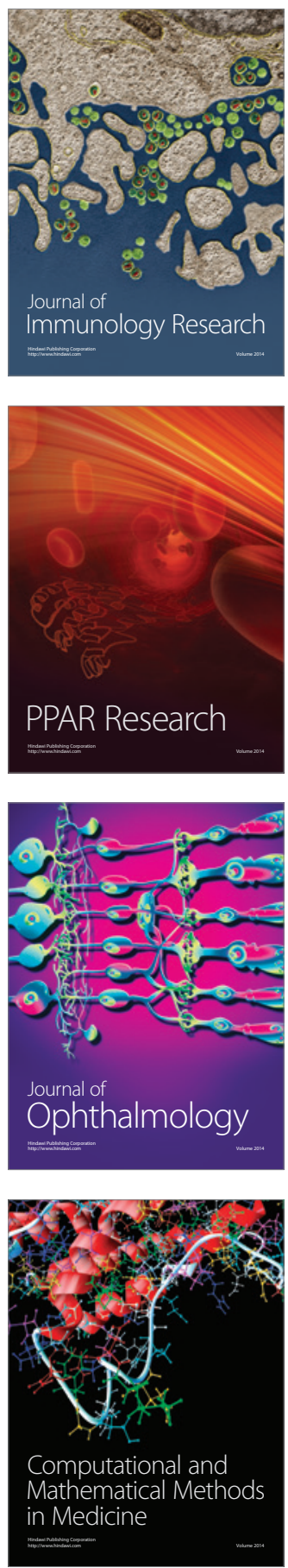

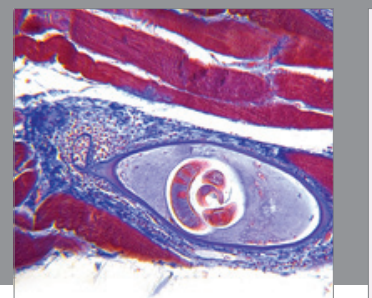

Gastroenterology

Research and Practice
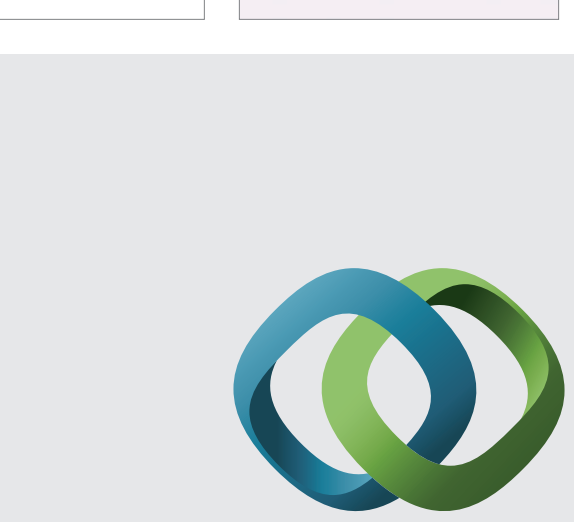

\section{Hindawi}

Submit your manuscripts at

http://www.hindawi.com
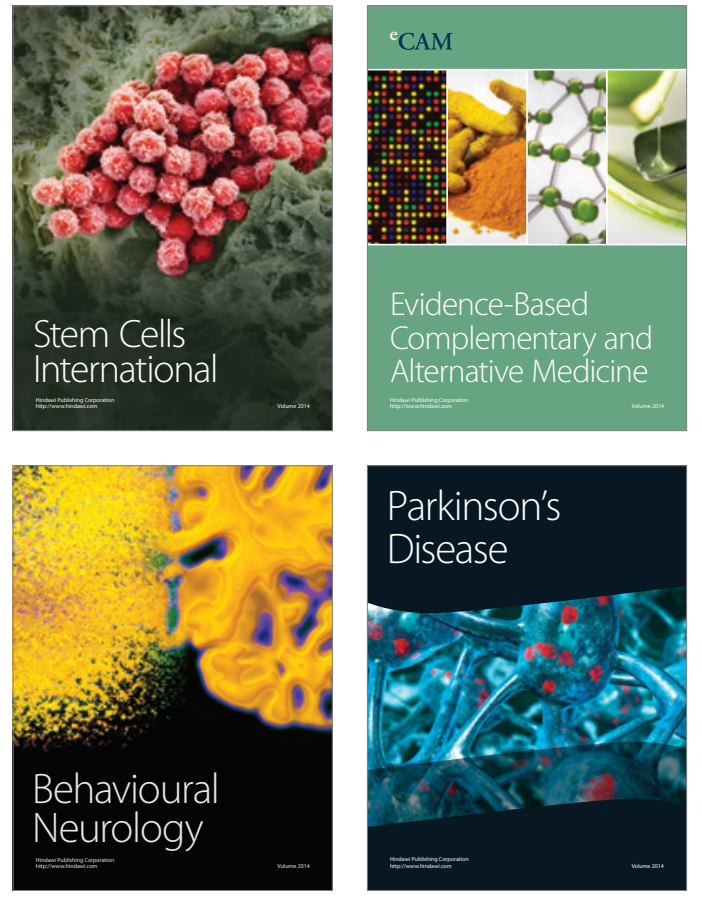
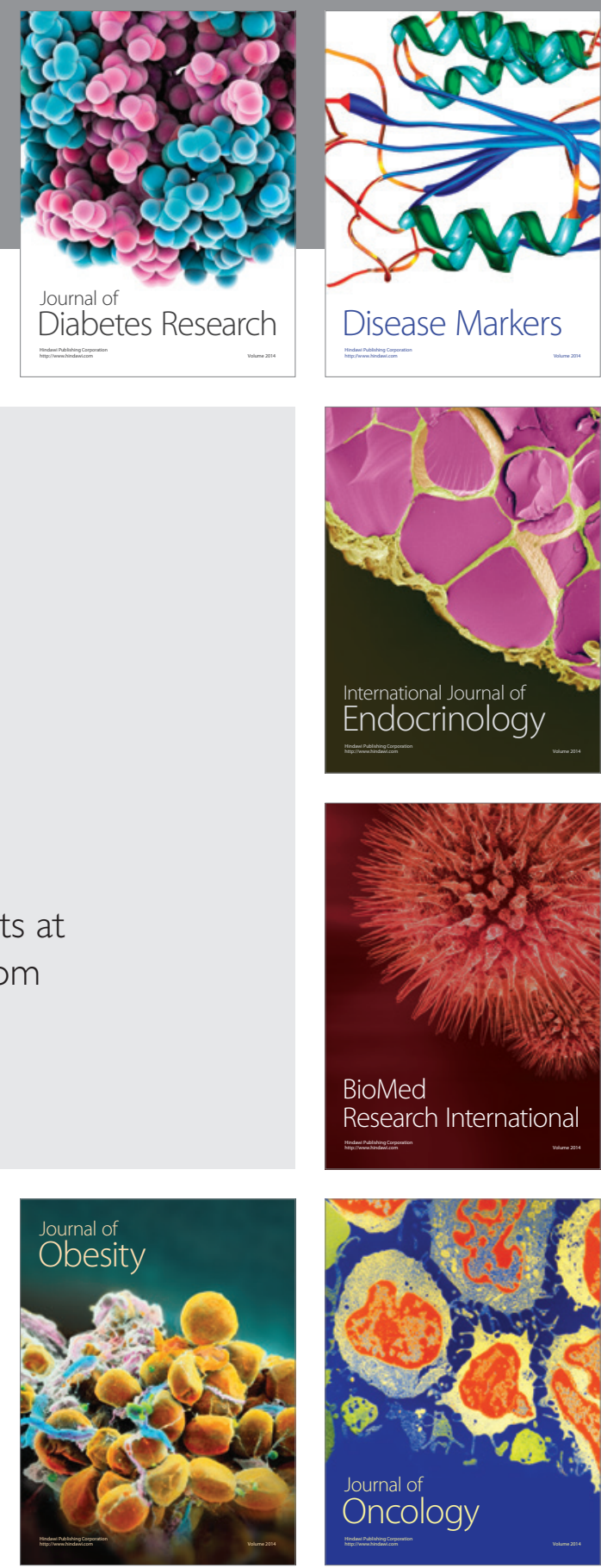

Disease Markers
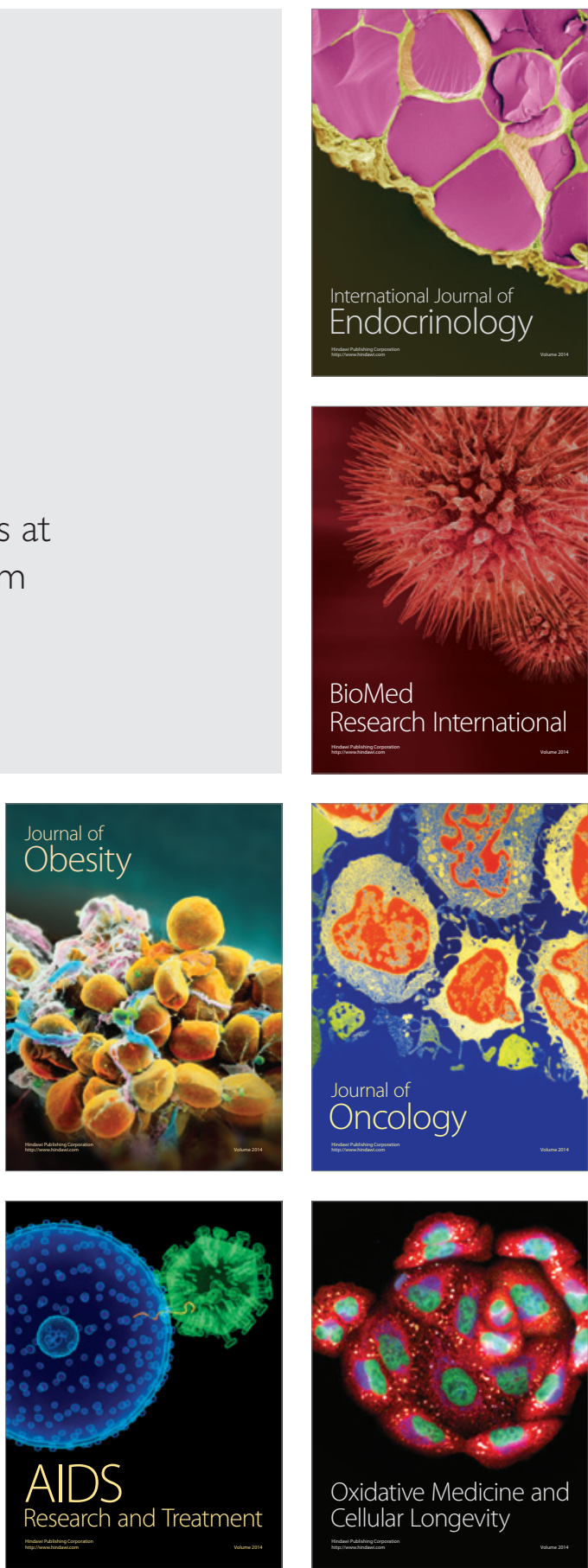